\title{
PENGELOLAAN PRAKTEK KERJA INDUSTRI (PRAKERIN) SISWA JURUSAN PERHOTELAN SMK NEGERI 6 PADANG
}

\author{
Asnidar, Yuliana \\ Progam Studi D4 Manajemen Perhotelan \\ Jurusan Pariwisata \\ Fakultas Pariwisata dan Perhotelan Universitas Negeri Padang \\ Email: asmidar1965@gmail.com
}

\begin{abstract}
The background of this research, the low impact resulting from the activities of Industrial Work Practices (PRAKERIN) Students Programs Hospitality SMKN 6 Padang, This looks at the mistakes that occurred in the industry such as the student could not comply with the rules established in the hotel some hotels are return students back to school and there are also students who make a quiet Testament error made and supply activities preparation of students not prakerin according to what will be done in the industry, This type of research is qualitative descriptive method ata collection techniques are observation, interview and documentation. The data analysis technique that is data reduction, display data, conclusion and verification. The results of this study portray that (1) Planning a briefing given to the students is still less than the maximum. (2) The implementation of activities of Industrial Work Practices own good, but the implementation there are students who are lazy. (3) prakerin ratings given to tutor students are nice, but for the procedure of granting the student prakerin value assessment takes time to ask.Because to get that value students must complete the assigned activity journal from the beginning.
\end{abstract}

Keywords: Activities of Industrial Work Practices (PRAKERIN), SMKN 6 Padang) 


\section{PENDAHULUAN}

Pola pendidikan sistem ganda dipilih sebagai model yang ideal untuk penyelenggaraan pendidikan kejuruan. Pendidikan kejuruan merupakan pendidikan menengah yang mempersiapkan peserta didik terutama untuk bekerja dalam bidang tertentu, sedangkan pendidikan vokasi merupakan pendidikan tinggi yang mempersiapkan peserta didik untuk memiliki pekerjaan dengankeahlian terapan tertentu maksimal setara dengan program sarjana

Sesuai dengan Keputusan Menteri Pendidikan dan Kebudayaan Republik Indonesia Nomor 323/U/1997 "Praktik Sistem Ganda (PSG) merupakan salah satu bentuk penyelenggaraan pendidikan keahlian professional yang memadukan teori dan praktek.

Menurut Anwar (2014:1) bahwa "Praktek kerja industri merupakan bentuk pendidikan dan kepelatihan keahlian kejuruan yang secara sistematis dan sinkron antara program pendidikan di sekolah dengan program penguasaan keahlian yang diperoleh melalui kegiatan bekerja langsung didunia kerja”.

Tugas dari pengelolaan praktek lapangan yaitu mengatur dan mengurus setiap kegiatan praktik mulai dari perencanaan, pelaksanaan sampai dengan penilaian prakerin. sehingga sekolah merasa bertanggug jawab terhadap siswa yangmelaksanakan paktek kerja industri yang dilakukan oleh siswa. Secara umum masalah pengelolaan praktek kerja industri biasanya dimulai dari perencanaan, pelaksanaan dan penilaian Dalam pengelolaan prakerin sekolah harus menyediakan fasilitas kepada siswa maupun guru pembimbing prakerin untuk melaksanakan kegiatan tersebut, dan sekolah juga harus memantau keseriusan siswa dalam melaksanakan prakerin serta sekolah melakukan pengantaran dan monitoring siswa yang melaksanakan prakerin.

Salah satunya adalah Sekolah Menengah Kejuruan Negeri 6 Padang. SMK Negeri 6
Padang, beralamat di Jalan Suliki No.1 Padang. SMK N 6 Padang dahulunya bernama Sekolah Kepandaian Putri (SKP) yang didirikan pada tahun 1962, kemudian berubah menjadi SKKA, lalu SMKK dan pada tahun 1997 berubah nama menjadi SMK Negeri 6 Padang. SMK Negeri 6 Padang merupakan SMK kelompok pariwisata, yang memiliki 6 kompetensi keahlian yang terdiri dari: (1) Kuliner (Tata Boga dan Pati Seri), (2) Tata Busana, (3) Tata Kecantikan Rambut, (4) Tata Kecantikan Kulit, (5) Kepariwisataan (Akomodasi Perhotelan dan Usaha Perjalanan Wisata), (6) dan ada satu juruan Teknik Komputer dan Jaringan (TKJ).

Berdasarkanhasil wawancara dengan Kepala Sekolah SMK Negeri 6 Padang, dapat dijelaskan bahwa Hotel adalah mitra kerja industri yang paling banyak digunakan sebagai tempat prakerin dibandingkan mitra kerja industri yang lainnya khususnya bagi Jurusan Perhotelan. Sehingga untuk menunjang keterampilan dari siswa perlu adanya Prakerin. Pelaksanaan Praktek Kerja Industri dilaksanakan oleh siswa kelas XI.Karena siswa kelas XI melakukan prakerin industri ini sesuai dengan tuntutan kurikulum 2013.Prakerin biasanya dilaksanakan selama 4 hingga 6 bulan.Hal ini dapat dilihat pada tabel 1 di bawah, dimana terdapat jenis-jenis industri penempatan siswa untuk prakerin.

Tabel 1. Jenis Industri yang digunakansebagai Tempat Praktek

\begin{tabular}{|c|l|c|}
\hline $\mathbf{N}$ & \multicolumn{1}{|c|}{ Jenis Industri } & Jumlah \\
\hline 1 & Hotel & 17 \\
\hline 2 & Biro Perjalanan Wisata & 15 \\
\hline 3 & Restaurant/cafe/catering & 1 \\
\hline 4 & Butik / Industri tekstil & 10 \\
\hline 5 & Salon \& Spa & 11 \\
\hline 6 & Pusat Telekomunikasi & 4 \\
\hline 7 & $\begin{array}{l}\text { Badan / Instansi } \\
\text { Pemerintahan/ Badan }\end{array}$ & 5 \\
\hline
\end{tabular}




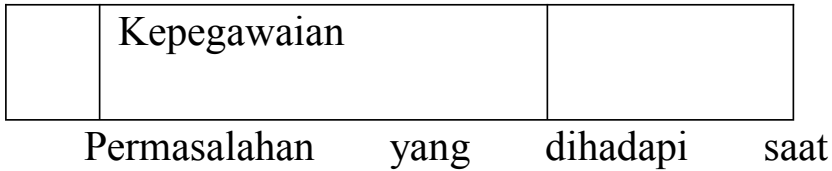

penyelenggaraan praktek kerja industri yaitu masalah pertama kegiatan pembekalan persiapan siswa prakerin tersebut tidak sesuai dengan apa yang akan dilakukan di industri.Persiapan pembekalan prakerin yang dilakukan masih kurang maksimal, karena pembekalan prakerin hanya diberikan dalam satu kali pertemuan saja dan materi yang disampaikan tidak terkhusus tentang materi pembekalan kegiatan kerja di industry

Masalah kedua tidak semua siswa bisa ditempatkan praktek sesuai dengan keinginan dan kemampuan siswa.Kebanyakan siswa hanya ditempatkan pada bagian Housekeeping departemen saja dan tidak dapat mencoba departemen lainnya yang ada di hotel. Pihak hotel tidak memberikan pertukaran departemen kepada siswa tersebut untuk belajar di departemen lainnya

Masalah ketiga banyak dari siswa yang mendapatkan masalah ketika pelakasanaan Prakerin, hal ini bisa dilihat dari beberapa hotel yang memulangkan siswa kembali ke sekolah dan melakukan ada juga siswa yang membuat surat perjanjian tenang kesalahan yang diperbuat.

Masalah keempat kegiatan monitoring dan penjemputan siswa setelah selesai magang tidak sepenuhnya terlaksanakan. Hal ini bisa dilihat dari sebagian guru pembimbing tidak menjemput siswa yang akan berakhir kegiatan prakerinnya, dikarenakan guru pembimbingsulit untuk menyesuaikan jadwal penjemputan siswa dengan jam kewajiban mengajar pelajaran kelas lain yang sedang berlangsung pada semester tersebut.Sementara jadwal siswa sudah berakhir dan siswa harus masuk kesekolah. Berdasarkan uraian di atas mendorong peneliti untuk mengangkatpenelitian dalam bentuk skripsi dengan judul "Pengelolaan Praktek Kerja

\section{Industri (Prakerin) Siswa Jurusan Perhotelan SMK Negeri 6 Padang".}

\section{METODE}

Sesuai dengan permasalahan penelitian dan pendapat para ahli diatas maka, penelitian ini bertujuan untuk memberikan gambaran, mengumpulkan pendapat dan mengungkapkan bagaimana pengelolaan praktek kerja industri (prakerin) jurusan perhotelan SMKN 6 Padang. Rancangan peneliti ini melibatkan 1 variabel yaitu prakerin dilihat dari 3 indikator yaitu: perencanaan program prakerin, pelaksanaan program prakerin, penilaian prakerin.

Menurut Sugiyono (2013:225) Dalam penelitian kualitatif, pengumpulan data dilakukan pada natural setting (kondisi yang alamiah), sumber data primer, dan teknik pengumpulan data lebih banyak pada observasi, berperan serta (participant observation), wawancara mendalam dan dokumentasi. Jadi teknik pengumpulan data yang akandilakukan pada penelitian ini yaitu: observasi / pengamatan, wawancara dan dokumentasi

Analisis data yang digunakan adalah model Miles and Huberman. Miles dan Huberman (1984) mengemukakan bahwa aktifitas dalam analisis data kualitatif dilakukan secara interaktif dan berlangsung secara terus menerus sampai tuntas, sehingga datanya sudah jenuh. Aktivitas dalam analisis data yaitu data reduction, data display, data conclusion drawing.

\section{HASIL PENELITIAN DAN PEMBAHASAN Hasil Penelitian}

Temuan dalam penelitian ini di bagi dalam dua jenis: 1) temuan umum yang bersifat menyeluruh, 2) temuan yang bersifat khusus tentang pengelolaan praktek kerja industri (prakerin) jurusan perhotelan SMKN 6 Padang

\section{Temuan Umum}

Pelaksanaan prakerin ini peneliti lakukan di SMK Negeri 6 Padang, dimana peneliti melakukan penelitian mulai dari perencanaan 
programprakerin, pelaksanaan program prakerin sampai dengan penilaian prakerin. Pelaksanaan prakerin yang dilakukan oleh SMK Negeri 6 Padang yaitu di industri hotel yang sesuai dengan bidang keahlian terutama bidang keahlian perhotelan. Hotel yang menjadi tempat pelaksanaan prakerin yaitu hotel berbintang di atas tiga yaitu hotel: (1) Kyriad Bumiminang (2) Basko Premier (3) Amaris (4) Ibis (5) Pangeran Beach (6) Aliga (7) Grand Zuri Padang (8) Rangkayo Basa dan hotel (9) Hang Tuah

\section{Temuan Khusus}

\section{a. Perencanaan Program Prakerin}

1) Pengaturan Pelaksanaan Prakerin Prakerin dilaksanakan selama 4 sampai 6 bulan pada siswa kelas XI. Pengaturan pengoorganisasian pembekalan persiapan pelaksanaan prakerin dikoordinasikan dari waka kurikulum lanjut pada humas, dari humas lanjut ke kaproka dan dari kaproka lanjut dengan ketua program umum

2) Pembekalan Peserta Prakerin

Pembekalan peserta prakerin menunjukkan bahwa perencanaan pemberian pembekalan prakerin kepada siswa dilakukan dengan cara memberi tahu kepada siswa tentang materi prakerin. Pemberian pembekalan ini dilakukan 2 minggu sebelum pelaksanaan prakerin. Pengaturan pengoorganisasian materi pembekalan prakerin dilakukan dengan cara mendata siswa prakerin tentang jurnalnya, tempat prakerin, siapa pembimbing dan kapan dilakukan pembekalannya dan materi yang akan disampaikan dikoordinasi dengan kaproka

3) Penetapan Pembimbing

Penetapan pembimbing diatur oleh kaproka dan humas yang ada disetiap program keahlian. Pengaturan pengoorganisasian penetapan pembimbing dilakukan dengan cara semua guru produktif dilibatkan. Penanggung jawab penetapan pembimbing dalam pelaksanaan prakerin, yaitu waka humas dan kaproka atas saran dari ketua jurusan

4) Uraian Tugas Pembimbing Sekolah dan Industri

Perencanaan tugas pembimbing sekolah dan industri dalam pelaksanaan prakerin dilakukan dengan cara tugas pembimbing untuk mengonrol siswa yang sedang prakerin di industri. Bentuk pengoorganisasian tugas pembimbing sekolah dan industri dapat dilihat dari surat tugas, buku monitoring. Yang bertanggung jawab dalam memberikan tugas pembimbing sekolah dan industri adalah wakil humas

\section{b. Pelaksanaan Program Prakerin}

1) Jurnal Kegiatan Prakerin

Pengisian jurnal kegiatan siswa dalam pelaksanaan prakerin dapat dilakukan dengan cara membaca isi jurnal tersebut, serta meninjau kegiatan sehari-hari siswa tersebut. Pengoorganisasian pengisian jurnal kegiatan ini dapat dilakukan dengan cara diisi oleh department masing-masing dan yang bertanggung jawab dalam pengontrolan jurnal kegiatan ini adalah supervisor di department siswa prakerin

2) Dokumentasi Portopolio Prakerin

Dokumentasi portopolio dalam pelaksanaan prakerin dan pengaturan pengoorganisasian dokumen portopolio kepada siswa dapat dilakukan dengan cara menyerakan pada deptbhead masing-masing dan yang bertanggung jawab dalam dokumentasi portopolio pelaksanaan prakerin adalah human resources selaku penerimaan siswa prakerin dan supervisor. Cara pengontrolan pembuatan dokumentasi portopolio pelaksanaan prakerin dilakukan dengan menyerahkan kepada dept head masing-masing

\section{c. Penilaian Prakerin}

1) Penilaian peserta didik 
Penilaian siswa menunjukkan bahwa Cara merencanakan penilaian dalam kegiatan ini yaitu dengan cara belajar semaksimal mungkin, apabila ada sesuatu yang tidak dimengerti menanyakan kepada senior. Cara mengatur pengoorganisasian jurnal penilaian ini yaitu menyelesaikan setelah prakerin dan melaksanakan pengisian buku jurnal, dan yang bertanggung jawab dalam pemberian penilaian terhadap jurnal yang kami buat adalah HRD personalia atau supervisor. Cara mengontrol jurnal penilaian pelaksanaan prakerin ini dengan cara pengisian jurnal dilakukan setiap hari setelah bekerja dan jika apabila ada yang kuranng kami menanyakan kepada supervisor.

2) Pelaporan Nilai Prakerin dalam Rapor

Pelaporan Nilai Prakerin dalam Rapor menunjukkan bahwa merencanakan pelaporan nilai prakerin tersebut dengan memberikan laporan selama prakeri kepada wali kelas. Mengatur pengoorganisasian pelaporan nilai dilakukan setelah selesai prakrin meminta nilai kepada supervisor dan langsung diberikan ke pembimbing baru ke wali kelas dan yang bertanggung jawab dalam pelaporan nilai ini adalah guru pembimbing dan wali kelas

3) Monitoring dan Evaluasi Pelaksanaan Prakerin

Merencanakan monitoring dan evaluasi dengan melakukan pertemuan dengan pembimbing sekolah dan industri minimal 2 bulan sekal. Pengoorganisasian monitoring dan evaluasi kegiatan ini dilakukan dengan cara melakukan komunikasi baik dari guru pembimbing maupun dari pihak industri dan yang bertanggung jawab dalam kegiatan ini adalah pembimbing sekolah dan industry

\section{Pembahasan}

\section{PerencanaanProgram Prakerin}

Dari segi hasil wawancara terlihat bahwa kegiatan pembekalan persiapan prakerin sudah bagus, namun perencanaan pembekalan yang diberikan terhadap siswa masih kurang maksimal.Kegiatan pembekalan persiapan yang diberikan kepada siswa hanya memerlukan waktu 1 hari saja, dan itupun siswa hanya mendengarkan nasehat-nasehat untuk meghadapi praktek kerja di industri. Kegiatan pembekalan persiapan prakerin yang akan diberikan kepada siswa, sebaiknya dilakukan 3 atau samapai dengan 6 hari, agar materi-materi yang diberikan dapat siswa terapkan di industri dan tidak banyak lagi dari siswa tersebut yang malas untuk tidak mengikuti kegiatan prakerin tersebut.

Hal ini sesuai yang dikatakan Menurut Oetomo (2002:2) bahwa "Unsur manajemen (pengelolaan) adalah Planning meliputi pengaturan tujuan dan mencari cara bagaimana untuk mencapai tujuan tersebut. Planning telah dipertimbangkan sebagai fungsi utama manajemen dan meliputi segala sesuatu yang manajer kerjakan. Di dalam planning, manajer memperhatikan masa depan, mengatakan ini adalah apa yang ingin kita capai dan bagaimana kita akan melakukannya".

\section{Pelaksanaan Program Prakerin}

Dari segi hasil wawancara terlihat bahwa pelaksanaan kegiatan prakerin sudah baik, namun pelaksanaan kegiatan prakerin masih terdapat siswa yang malas dalam pelaksanaan prakerin tersebut.Terdapatnya siswa yang masih malas dalam melakukan pelaksanaan prakerin dikarenakan karena pada saat Persiapan sebelum melaksanakan prakern siswa banyak yang menganggap kegiatan ini hanya main-main saja dan 
mereka juga menganggap kegiatan ini hanya memperbanya tugas yang diberikan.Tugas yang diberikan dalam pelaksaan prakerin seperti pembuatan jurnal kegiatan.Lemahnya semangat siswa dalam pelaksanaan kegiatan prakerin ini membuat siswa menjadi malas untuk sering tidak masuk atau kurang untuk mengikuti peraturan yang ada di industri.

Hal ini sesuai dengan teori Menurut Oetomo (2002:2) bahwa "Unsur manajemen (pengelolaan) meliputi Actuating adalah peran sekolah dan industri untuk mengarahkan siswa yang sesuai dengan tujuan organisasi.Actuating adalah implementasi rencana, berbeda dari planning dan organizing.Actuating membuat urutan rencana menjadi tindakan dalam dunia organisasi. Sehingga tanpa tindakan nyata, rencana akan menjadi imajinasi atau impian yang tidak pernah menjadi kenyataan.

\section{Penilaian Prakerin}

Dari segi hasil terlihat bahwa penilaian prakerin yang diberikan siswa terhadap guru pembimbing bagus, namun untuk prosedur pemberian penilaian nilai prakerin siswa tersebut membutuhkan waktu untuk memintanya.Karena untuk mendapatkan nilai tersebut siswa harus menyelesaikan jurnal kegiatan yang ditugaskan dari awal. Oleh karena itu, perlu monitoring dan evaluasi dari guru pembimbing untuk menyuruh siswa tersebut dalam menyelesaikan jurnal kegiatan prakerin, agar bias mendapatkan nilai yang baik. Hal ini sesuai dengan pendapat

Menurut Oetomo (2002: 2), "Unsur manajemen (pengelolaan) meliputi controling yaitu memastikan bahwa kinerja sesuai dengan rencana. Hal ini membandingkan antara kinerja aktual dengan standar yang telah ditentukan. Jika terjadi perbedaan yang signifikan antara kinerja aktual dan yang diharapkan, sekolah dan industri harus mengambil tindakan yang sifatnya mengoreksi atau mengevaluasi”

\section{PENUTUP}

\section{Simpulan}

1. Perencanaan program prakerin sudah bagus, namun perencanaan pembekalan yang diberikan terhadap siswa masih kurang maksimal. Kegiatan pembekalan persiapan yang diberikan kepada siswa hanya memerlukan waktu 1 hari saja, dan itupun siswa hanya mendengarkan nasehat-nasehat untuk meghadapi praktek kerja di industri.

2. Pelaksanaan program prakerin sudah baik, namun masih terdapat siswa yang malas dalam pelaksanaan prakerin tersebut. Terdapatnya siswa yang masih malas dalam melakukan pelaksanaan prakerin dikarenakan karena pada saat Persiapan sebelum melaksanakan prakern siswa banyak yang menganggap kegiatan ini hanya main-main saja dan mereka juga menganggap kegiatan ini hanya memperbanyak tugas yang diberikan.

3. Penilaian prakerinyang diberikan siswa terhadap guru pembimbing bagus, namun untuk prosedur pemberian penilaian nilai prakerin siswa tersebut membutuhkan waktu untuk memintanya. Karena untuk mendapatkan nilai tersebut siswa harus menyelesaikan jurnal kegiatan yang ditugaskan dari awal.

\section{Saran}

1. Bagi pihak sekolah agar dapat melakukan persiapan pengelolaan prakerin guna untuk meningkatkan semangat siswa untuk melakukan kegiatan prakerin.

2. Bagi pihak industri agar lebih memberikan kesempatan kepada para siswa untuk lebih memperdalam ilmu dan pengalaman siswa dengan mencoba berbagai department dalam pelaksanaan prakerin. 
3. Bagi jurusan Pariwisata khususnya mahasiswa D4 Manajemen Perhotelan dapat menjadikan penelitian ini sebagai bahan reverensi untuk melakukan penelitian lebih lanjut.

4. Bagi peneliti selanjutnya untuk dapat meneliti tentang Pengelolaan Praktek Kerja Industri (PRAKERIN) Siswa Jurusan Perhotelan.

\section{DAFTAR PUSTAKA}

Anwar. 2014. Pendidikan Kecakapan Hidup (Life Skill Education). Bandung: Alfa Beta.

Bondan, Arum Pratiwi. 2009. Pengaruh Praktik Kerja Industri dan Prestasi Belajar Akuntansi terhadap Kesiapan Kerja Siswa Kelas XII SMK N 1 Banto tahun ajaran 2009/2010.Skripsi. Yogyakarta: Pendidikan Akuntansi UNY.

Damayanti, Elling. 2014. Manajemen Praktek Kerja Industri pada Kompetensi Keahlian Administrasi Perkantoran di SMK SeYogyakarta.Skripsi.Yogyakarta. Fakultas Ilmu Pendidikan UNY.

Kamus Besar Bahasa Indonesia (KBBI) tentang pengertian praktik. Jakarta

Keputusan Menteri Pendidikan dan Kebudayaan Indonesia Nomor 323 / U / 1997, Pasal 1 Ayat 1 : Praktik Sistim Ganda (PSG) merupakan salah satu bentuk penyelenggaraan pendidikan keahlian profesional yang memadukan secara sistematik dan sinkron program pendidikan disekolah.

Kurikulum SMK edisi 2004. Pendidikan Sistem Ganda.Jakarta : Kementrian Pendidikan.

Pedoman Paktik Kerja Lapangan. 2017. Praktek Kerja Lapangan. Padang: Kementrian Pendidikan dan Kebudayaan.
Peraturan Pemerintah No. 29 Tahun 1990 tentang Pendidikan Menegah Bab 1 Pasal 1 ayat 3 .

Subroto, Darwanto Sastro. 2010. Televisi Sebagai Media Pendidikan.Pustaka Pelajar Offset : Yogyakarta.

Sugiyono. 2013.Metodologi Penelitian Kuantitatif Kualitatif dan $R \& D$. Bandung: Alfabeta 